\title{
Towards A Model Of Charismatic Non-Verbal Impression Management
}

\author{
Raed Awamleh (Email: RaedAwamleh@uowdubai.ac.ae), University of Wollongong Dubai Campus, UAE
}

\begin{abstract}
Although evidence of charismatic leaders handling of non-verbal and expressive behaviors to manage impressions exists in literature, a conceptual framework for understanding this process is not available. Thus, the purpose of this paper is to propose such a framework which draws upon and integrates the literatures in the areas of charismatic leadership, impression management, and non-verbal behavior. More specifically, the proposed model focuses on addressing the question of how do charismatic leaders utilize non-verbal behaviors to manage the impressions formed of them by followers in order to promote and enhance the charismatic relationship. As part of the model, this paper advances ten specific propositions that can form the base for future research initiatives.
\end{abstract}

\section{Introduction}

D espite all of the attention to test and operationalize charismatic leadership attributes (e.g., Awamleh \& Gardner, 1999 House, 1977; Conger \& Kanungo, 1987; Bass, 1985; Shamir, 1991;), our understanding of some critical facets of charismatic leadership remains somewhat imprecise. One area that remains largely unexplored, is the use of non-verbal behaviors by charismatic leaders to manage others' impressions of them.

Although evidence of charismatic leaders handling of non-verbal and expressive behaviors to form impressions exists in literature (e.g. Bass \& Stogdill, 1990; House \& Howell, 1992), a specific analysis of this process is not available. In particular, while Gardner and Avolio (1998) have advanced an impression management perspective that examines the charismatic relationship, their model focused primarily on verbal impression behavior. Hence, the purpose of this paper is to advance a charismatic non-verbal impression behavior framework that draws upon and integrates the literatures focusing on: 1) charismatic leadership, 2) impression management, and 3) nonverbal behavior. More specifically, the model presented is primarily addressing the following research question: "how are non-verbal behaviors used by charismatic leaders to help manage the impressions formed of them in faceto-face interactions with followers?"

This paper will begin by establishing background linkages between the various constructs included in the model by reviewing relevant literature. Next, the model is presented and its propositions are discussed. Finally, conclusions and suggestions for future research are provided.

\section{Origins of Charisma}

Unlike other types of leadership, charismatic leadership is derived from faith in the leader's exemplary character Conger and Kanungo (1987). Furthermore, as Max Weber stated, "the charismatic is set apart from ordinary men and treated as endowed with supernatural, superman, or at least exceptional powers and qualities [which] are not accessible to the ordinary person but are regarded as of divine origin or as exemplary, and on the basis of them the individual concerned is treated as a leader (Conger \& Kanungo, 1987: 12). Moreover, charisma depends on followers as well as leaders (Bass, 1985). Indeed, the extent to which followers will show admiration, affection and trust depends on the leader's personality and their perception of it.

Readers with comments or questions are encouraged to contact the author via email. 


\section{Impression Management by Leaders}

House (1977) was the first to formulate the concept of personal image building where charismatic leaders engage in impression management to convey images of competence and success. Building on this notion, several authors have emphasized the fact that leaders engage in impression management to gain follower's faith in them and to elevate their images of competence and credibility (e.g., Conger \& Kanungo, 1987; Bass, 1985). Likewise, Leary (1989) recognized the importance of impression management to leadership proposing that a crucial factor of leader effectiveness is the maintenance of appropriate leader relevant images. Furthermore, Leary (1989) noted that leaders foster desired impressions through non-verbal behaviors. Examples of non-verbal behaviors include physical appearance, eye contact, touching, and facial expressions.

\section{Non-Verbal Forms of Impression Management}

Non-verbal behavior is a powerful tool for conveying impressions and sending messages about oneself to others (e.g. Schlenker, 1980; Jones \& Pittman, 1982; Gardner \& Martinko, 1988; Schlenker \& Weigold, 1992). DePaulo (1992) conducted a thorough literature review of the role of non-verbal behavior in self-presentation. She concluded that people will be more successful in conveying desired impressions when they use non-verbal cues in concert with verbal cues even if these impressions were inaccurate. It has also been shown that when verbal and non-verbal messages are incongruent, the non-verbal ones will prevail in forming impressions (Leathers, 1976; Remland, 1981; Miller, 1988).

A number of empirical studies have indicated the importance of non-verbal behavior to charismatic leadership. For example, Gitter, Black, and Fishman (1975) studied the effects of verbal and non-verbal communication on perceptions of leadership. These authors concluded that when pit against each other, non-verbal communications exerted more potent effects than verbal communications on perception of leadership. More recently, Beattie and Shovelton (2002) found that the communicative power of gestures is significantly affected the viewpoint from which a gesture is generated, suggesting that actors can invoke specific reactions from observers when they actively manage non-verbal cues.

\section{Fundamental Properties of Non-Verbal Behavior}

Communication researchers maintain that there is a set of unique properties of non-verbal behavior that have important implications for the process of impression formation (DePaulo, 1992; Leathers, 1976; Miller, 1988). In particular, DePaulo, (1992) summarizes four basic properties that are extremely relevant to self-presentation. The first, and perhaps most important, is that non-verbal behavior is irrepressible. It is almost impossible for one to avoid non-verbally conveying some kind of impression. This implies that leaders, whether they like it or not, send messages even when they do nothing. Second, non-verbal behavior is off the record. People may be able to recount the words of others, but they have difficulty reproducing expressive behaviors (e.g., facial expressions). Third, nonverbal behavior conveys unique meanings that cannot be communicated by words. Finally, non-verbal behavior occurs very quickly; it is almost instantaneous.

\section{A Classic Example: Nixon-Kennedy Debates}

To illustrate the power of non-verbal communication, an example can be drawn from the political arena. It is believed that the 1960 Nixon-Kennedy televised debates were the most intensively studied communication event in history. Harrison (1974) suggests that what was most interesting about this event is that people who heard the debate on radio or read the full text thought it was a draw. However, those who saw the debate on television thought Kennedy won. Viewers saw Kennedy as strong, colorful, handsome and relaxed. While Nixon was seen as old, tense, shallow and colorless. 


\section{Overview Of The Charismatic Impression Management Model: The Non-Verbal Behavior Approach}

In developing the proposed model (see figure 1), an interactionist perspective is adopted to reflect the true relationship between the charismatic leader, follower, environment, and behavior (both verbal and non-verbal). In effect, this model adopts Goffman's (1959) dramaturgical framework, where charismatic leaders are viewed as actors who perform before audiences in different settings.

FIGURE 1: A Model of Charismatic Non-verbal Impression Management

"Actor"

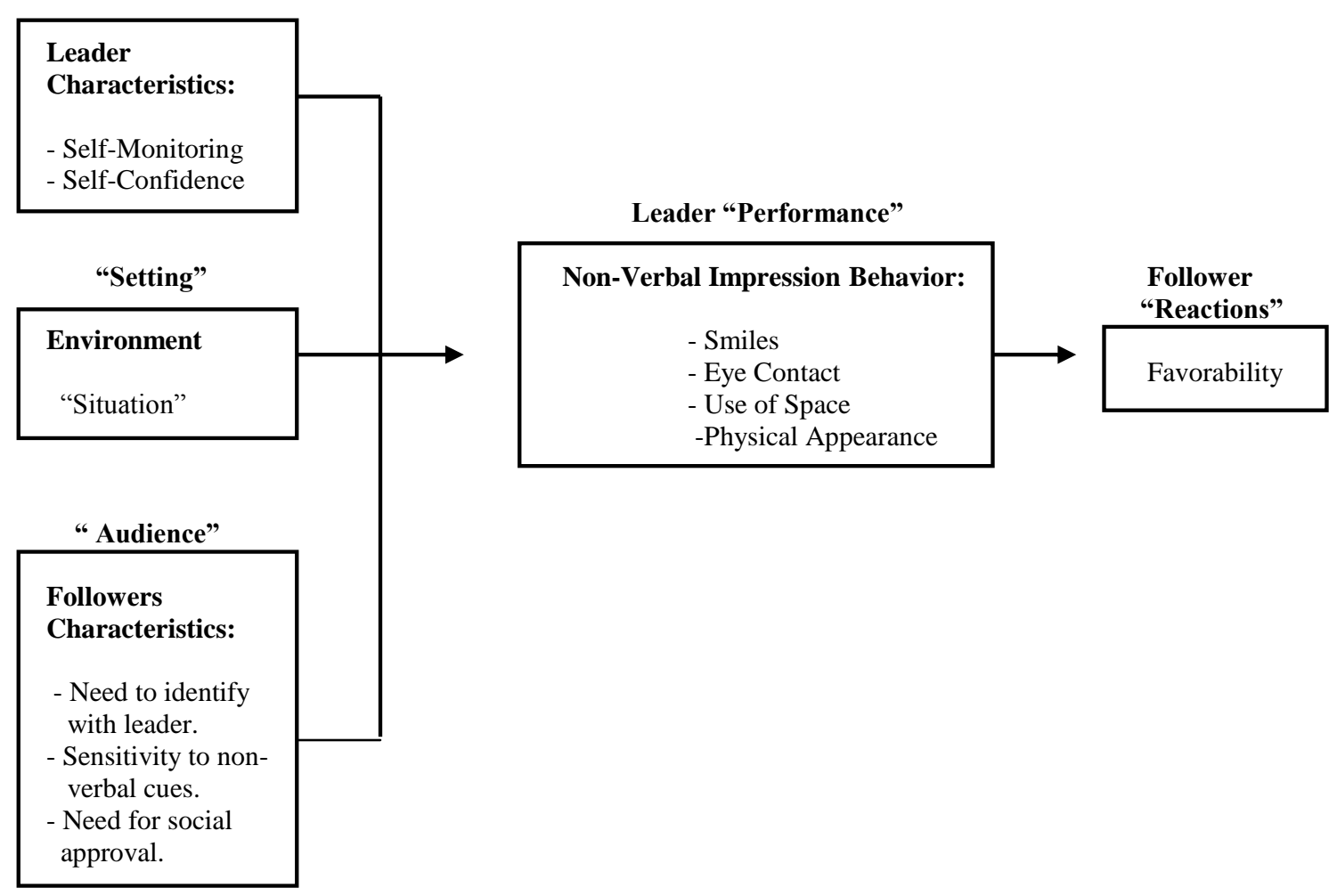

As shown in the model, attributes of the environment interact with those of the charismatic leaders and follower to shape the form of non-verbal behavior exhibited by the leader. Follower reactions are likewise influenced by their perceptions of the leader's behavior. The ultimate outcomes of the process are manifested in terms of follower behaviors.

It is believed that leaders, as social actors (Leary and Kowalski, 1990), continuously monitor their behaviors, audiences and situational cues at a pre-conscious level. When operating at this pre-conscious level, many of the leaders' non-verbal behaviors may be over learned and scripted, and hence not subject to conscious scrutiny. Many of these expressive behaviors are developed over time and become deeply ingrained. Even though they are not consciously enacted, they can be highly effective and thus become integral elements of the leader's performance. When automatic monitoring processes detect image relevant stimuli, the leader becomes more self-aware and expressive behavior is more likely to be strategically motivated. 


\section{Charismatic Leaders Attributes}

Charismatic leaders attributes include assertiveness, dominance, self-confidence, creativity, need for power, and strong conviction to the value of their own beliefs (Bass, 1985; House, 1977). Yet, leader attributes most relevant to non-verbal behavior are self-monitoring and self-confidence.

Self-monitoring. Self-monitoring refers to self-observation and self-control guided by situational cues of social appropriateness, it is defined as an actors' skill at monitoring and controlling verbal and expressive behaviors (Snyder, 1974). Individuals with high self-monitoring abilities are good at learning what is socially appropriate in new situations, have good self-control of their emotional expressions and can efficiently use this ability to create the impressions they want (Synder, 1974). For charismatics, self-monitoring is critical since they must continuously adjust their behavior to different situations and people. Charismatic leaders need to be sensitive to others and have the ability to understand followers (Bass, 1990). This indicates that the self-monitoring abilities of charismatic leaders are directly related to their skills at regulating non-verbal behavior.

While people with low self-monitoring abilities are not overly concerned about their self-presentations and expressive behavior in social interactions, high self-monitors are different. For instance, Friedman and MillerHerringer (1991) found that high self-monitors were successful at hiding their happiness when appropriate, while low self-monitors were unable to conceal their emotions. Moreover, as DePaulo (1992) noted, high self-monitors are sensitive to global variations in the requirements of different situations, roles and audiences. Hence, there is strong evidence to suggest that high self-monitoring skills will allow charismatic leaders to better adjust and use non-verbal behaviors across audiences and situations to convey desired impressions. Therefore. It is proposed that:

Proposition 1: High as opposed to low self-monitoring abilities help charismatic leaders to better monitor and control their non-verbal behavior.

Self-Confidence. Confidence is a must for people who desire to monitor and control their non-verbal communication DePaulo (1992). Importantly, current theory and research indicates that self-confidence is likewise a key attribute of charismatic leaders. As bass (1985: 45) notes, a universal trait of the charismatic leader is his own self-confidence and self- esteem . . . charismatics make this a clear aspect of their public image. In order for charismatics to influence others and carry out their mission, they need to have self-confidence; it is critical to their success (House, 1977; Conger \& Kanungo, 1988). Indeed, along with expressive behavior, Bass and Stogdill (1990) considered self-confidence to be a crucial trait of charismatics. For example, when they are under attack, confidence may help leaders control their behaviors to avoid self-defeating strategies. Instead of becoming overly self-conscious of their own non-verbal behavior, they will be more aware of the reactions of others (Hill, 1976). Therefore, it is believed that charismatic leaders' self-confidence will be particularly and directly related to their ability to efficiently manage their own non-verbal behaviors. This suggests that:

Proposition 2: Self-confidence allows charismatics to foster desired images through non-verbal behavior.

\section{The Environment}

Charismatic leaders are distinguished by their sensitivity to environmental constraints, sensitivity to follower's needs, and identification of deficiencies in the status quo (Conger \& Kanungo, 1988). Each aspect of the situation presents charismatic leaders with opportunities, to enhance their image, as well as threats that could damage it. Behaviors of charismatics will be influenced, in part, by the extent to which they accurately assess situations.

Charismatic leaders must also assess cultural norms. People from different cultures are likely to respond in different ways to non-verbal cues (e.g., Masters, 1991). For instance, a study by Ekman, Friesen, and Ellsworth (1982) of Japanese and American participants revealed that the groups exhibited different facial expressions in discussing stress films with an interviewer or alone. Clearly, different situation dictate which non-verbal expressions are appropriate and which are not. Accordingly, charismatic leaders are highly sensitive to environmental constraints 
that limit the range of expressive behaviors they can employ. That is, they will refrain from behaviors that might severely undermine their self-presentational strategies. Therefore, it may be proposed that:

Proposition 3: The environment and situational dimensions shape charismatic leader's non-verbal behaviors as well as followers reactions.

\section{Impression Management Behavior}

Non-verbal communications involve a wide range of behaviors. In the interest of parsimony, however, the focus of the proposed model is limited to four basic types: smiles, eye contact, use of space, and physical appearance. Concentrating on these cues is justified given their predominance within the literature on non-verbal communication in general (e.g., Miller, 1988) and leadership literature in particular (e.g., Remland, 1984).

\section{Smiles}

Among facial expressions, smiles are perhaps the most visible and frequent. In addition to happiness, smiles have been shown to be reflective of and contribute to immediacy, intimacy and warmth (Anderson, 1985; La France \& Hecht, 2000), and also of status (Hall, Horgan, \& Cater, 2002). Furthermore, they can increase interpersonal acceptance, communicate interpersonal affiliation, and are frequently reciprocated (Anderson, 1985). Furthermore, smiles may also be indicative of fear, contempt or compliance (DePaulo, 1992). In addition to spontaneously expressing emotions, smiles are used strategically by actors sometimes to influence others' actions (e.g. Ekman, Davidson, \& Fraise, 1990).

From an impression management perspective, regulated smiling is a powerful strategy. For instance, people who desire close and warm interactions with others smile more often than those who do not (McAdams, Jackson, \& Kirsshit, 1984). Moreover, several studies indicate that smiles can be used to ingratiate and gain the approval of others (e.g., Bugertal, 1986; Lefebvre, 1975). In a study of people's responses to the non-verbal communications of the 1984 presidential candidates, Sullivan and Masters (1988) concluded that people were greatly influenced by the candidates' displays of happiness. Remarkably, people's attitudes toward a candidate were more likely to be influenced positively by happy facial expressions than other variables such as issue agreement, party identification, or even assessment of leadership abilities. In a related study, Mchugo, Sullivan, Masters and Englis (1985) specifically examined Ronald Reagan's facial expressions and their effects on people. They found that when subjects were shown videotape segments in which Reagan displayed a happy face by smiling, the viewers smiled in return and expressed positive reactions. In contrast, Reagan's facial expressions that suggested fear or anger evoked negative reactions. These findings are particularly relevant to the study of charismatic leaders. Since charismatics seek to motivate, move and inspire followers, smiles represent a powerful means of achieving such outcomes. By regulating their smiles, charismatic leaders are able to convey the images of happiness and reassurance to which followers react most positively.

It is interesting to note that in addition to the direct effect of leaders' smiles, further benefits can accrue when others who speak of them smile. When one study examined the relationship between newscasters' facial expressions and viewers' voting behavior in U.S. presidential elections, it was found that voters were more inclined to vote for candidates for whom the newscaster smiled extensively while discussing (Mullen, Futrell, Stairs, Tice, Baumeister, Dawson, Riorden, Radloff, Geothals, Kennedy, \& Rosenfeld, 1986). This means that leaders benefit from paying particular attention to managing the impressions of opinion leaders, such as members of the media, since these key audiences may inadvertently convey their impressions to others through their facial expressions. Therefore, it is proposed that:

Proposition 4: Charismatic leaders use smiles to attract, reassure, and maintain the acceptance of followers. 


\section{Eye Contact}

As a primary channel for non-verbal communications, the eyes are considered to be the most dominant facial feature. The eye, described by poets as the window of the soul, serves as an essential tool for effective interpersonal communications (Harrison, 1974). Eye contact, often referred to as one's gaze, serves several purposes which include providing information, regulating interactions, expressing social control, and facilitating goals (Miller, 1988).

For charismatic leaders, the eyes can be their most striking feature, and they commonly use it to manipulate the feelings and influence the behavior of others (Webbink, 1986). Willner (1984) argued that charismatic leaders have powerful eyes, she indicated that however varied the [charismatic] leaders . . may have been in most aspects of their physical appearance . . . most of them seem to have shared the attributes of extraordinary eyes (p. 149). Hitler and Castro are known for their hypnotic eyes, Mussolini for his luminous eyes, and Reagan for his sincere looks. Referring to the legendary American football coach Vince Lambardi, who was famous for his aggressive leadership style, one former player once remarked "he looked at you in every second of every play, he looked you right in the eye, he looked through you, ... the man scared me to death". Eye contact, or gaze, helps charismatic leaders to captivate their audience and thus, elicit attributions of power and dominance (Webbink, 1986).

Research on eye behavior has revealed that people tend to look at actors whom they respect, trust, and like for comparatively longer periods of time (e.g. Durbin, 1985; Kleinke, 1986). As such, people are much more inclined to establish eye contact with persons with whom they feel comfortable. In conversation, speakers often maintain eye contact when emphasizing a particular point or looking for feedback, while listeners maintain eye contact to communicate their level of interest in the speaker and in the topic (Rosenfeld, 1976). For example, Exline and Winters (1965) demonstrated that job applicants maintain greater eye contact when the interviewer is evaluating them positively as opposed to negatively. Similarly, Ellsworth and Carlsmith (1968) found that frequent eye contact produced more favorable evaluations when accompanied by a positive as opposed to negative verbal content. This implies that eye contact can be used in concert with verbal communication to reinforce and emphasize a message. Charismatics can receive instant feedback from their audience based the level of eye contact (e.g., Rasmussen 1984) which allows them to make adjustments in their behavior to ensure effective communications.

Because charismatic leaders are usually the center of attention, it is vital for them to monitor the messages they send and receive through their eyes. There is evidence that extended eye contact is related to the impression of dominance (Strongman \& Champers, 1968) and is often perceived as a sign of leadership in small group discussions (Burroughs, Schultz, \& Autrey, 1973). Furthermore, Holladay and Coombs (1993) argue that charismatic leaders will be perceived as more credible when they maintain eye contact while speaking. Hence, charismatic leaders find it advantageous to maintain frequent eye contact to emphasize a point, captivate their audience, receive feedback, and create the impressions of dominance and credibility. Thus it is proposed that:

Proposition 5: Charismatic leaders use eye contact and gaze to foster images of power, dominance, credibility and to receive feedback.

\section{Use of Space}

Physical distance between individuals communicates a variety of messages. It can be seen as a sign of liking or disliking, trust or distrust, and personal versus impersonal subject matter (Harrison, 1974). Furthermore, Hall (1969) distinguished between three types of space: 1) fixed -feature space (e.g., immovable walls and objects), 2) semi-fixed feature space (e.g., chairs and tables), 3) informal space (interpersonal space).

Since the nature of the charismatic relationship tends to become highly personal, this section will concentrate on the third type of space; interpersonal space. In organizations, the leader's physical territory (e.g., offices) is usually less accessible than that of subordinates. Therefore, leaders often invade the space of their subordinates, while subordinates maintain greater distance (Henly, 1977). However, charismatics are special type of leaders. In motivating their followers, charismatics project a confident, powerful and dynamic presence (e.g., House, 
1977). Therefore, charismatic leaders are not expected to strictly adhere to social rules regarding spatial distances. Instead, they are likely to encourage followers to get close to them and act to reduce status differences. Support for this prediction is provided by Howell and Frost's (1989) laboratory study of charismatic leadership. To operationally produce charisma, professional actors were instructed to alternate between pacing and sitting on the edge of their desk and leaning toward the follower. Their results revealed that subordinates of charismatic leaders achieved higher levels of task performance and satisfaction and less role ambiguity. In addition, Remland (1984) found that subordinates perceived a leader to be more considerate in face-to-face interactions when status differences, including spatial distance, were reduced.

Remland (1981) speculates that through the proper use of space, leaders can reduce status differences with their followers and increase followers' self-esteem resulting in higher performance levels. Accordingly, we predict that charismatic leaders will maintain closer distance when communicating with followers in order to promote impressions of trust, confidence and personal relationships. Thus, it is proposed that:

Proposition 6: Charismatic leaders use personal space to reduce status differences, and hence, raising followers' self-esteem and establish personal relationships.

\section{Physical Appearance}

Physical appearance includes several components, such as attractiveness, dress, and grooming. Each offers actors a unique communication channel to foster desired imagers. For example, research has shown that attractive as opposed to unattractive people are more effective at communicating emotions and monitoring their non-verbal behaviors (DePaulo, Kirkendol, Tang, \& O'Brien, 1988). It was also documented that the physical attractiveness of the service provider elicits customers' perceptions of friendliness, credibility, and competence (Sundaram \& Webster, 2000).

Key attributes of an individual that are at least partially discernable from appearance include, sex, age, socioeconomic class, status, role, and group memberships. Furthermore, clothing can be reflective of one's attitudes, values and personality (Miller, 1988). Leather (1976) refuted the notion that physical appearance is of secondary and superficial value, arguing that it has a pervasive impact on one's self-image, and hence, plays a major role in shaping behavior. Moreover, physical appearance presents actors with a very useful channel of communication to make statements about themselves and the way that they want to be perceived. Indeed, there is extensive empirical support for the conclusion that one's self-image is almost always expressed through choices of dress and costumes.

In society, dress serves as a role definer. Judges, police officers, and pilots wear distinct uniforms that help them exercise their power and fulfill their duties. For charismatic leaders, dress serves a similar though less systematic purpose. In his book, theater of power, Chen (1987) proposed that leaders in general use dress to reflect four key purposes: 1) role definition, 2) indication of status, 3) identification with an ideology, and 4) reflection of mood.

Charismatic leaders are likely to rely heavily on their choice of dress to communicate desired messages. For example, Fidel Castro wore a beret to indicate revolution and national liberation. David Ben Gorion, one of Israel's founding fathers, dressed in plain Khaki to promote simplicity and the pioneering spirit. Similarly, the Bedouin koffiyah worn by the Palestinian leader Yasser Arafat has become internationally associated with the Palestinian struggle to resist Israeli occupation. Finally, Gandhi's physical appearance contributed to his image as a superhuman legend. Dressed in a simple white cloth nearly half naked, he was seen as a symbol of national liberation, sacrifice and non-violent resistance (Willner, 1984). Charismatics such as these realized the power of dress to communicate and reemphasize their vision. In all of these cases, the leader's attire serves as a constant reminder of goals and objectives, and perhaps most importantly, the central theme of their vision.

Any potential contradiction between a leader's verbal message and physical appearance represents a major obstacle to effective communication. Specifically, a charismatic leader's appearance should complement, and not detract, his or her desired identity images. Therefore, charismatic leaders are expected to be highly sensitive to the 
impressions formed of them based on physical appearance. They will capitalize on opportunities to favorably manipulate their appearance while carefully monitoring audience reactions. Accordingly, it is proposed that:

Proposition 7: Charismatic leaders manipulate their physical appearance (e.g., dress, grooming) to foster ideologically appropriate images and articulate/reinforce their vision.

\section{Need to Identify with the Leader}

A strong desire to identify with the leader has long been viewed as a distinguished characteristic of charismatic leader's followers (Bass \& Stogdill, 1990). Indeed, personal identification is a core principle of a number of charismatic leadership theories (Shamir, 1991). There are several reasons why followers come to exhibit strong psychological attachment to the leader. One is that they believe in the leader's mission. However, as Weber indicated, the leader's exemplary character is a critical component of a charismatic relationship. Leaders serves as role models whom followers try to emulate. Hence, it appears that as a consequence of this identification process, followers tend to be especially be attuned to the leader's behavior. As we have seen, a crucial element of such behavior, is non-verbal. Therefore, it can be deduced that the followers, as they come to identify with the leader, will be greatly influenced by the leaders' non-verbal behaviors. The preceding reasoning suggests:

Proposition 8: Followers need to identify with the leader increases their awareness of his or her non-verbal behaviors.

\section{Sensitivity to Non-Verbal Cues}

People vary with regards to the ways in which they interpret non-verbal behavior people (e.g., Nasby, Hyden \& DePaulo, 1980). Non-verbal behavior research provides evidence supporting the existence of individual differences in decoding non-verbal cues (Halberstadt, 1985). Indeed, sex, race, and socioeconomic status have been shown to affect the skill of reading those cues. For example, women are believed to be more skillful than men at decoding non-verbal messages (e.g., Hall, 1984). More specifically, they have been found to be more capable than men at reading covert cues that contain messages that people want to convey (Rosenthal \& DePaulo, 1989).

In her review of the literature on race, socioeconomic status and non-verbal behavior, Halberstadt (1985) concluded that race, class, and cultural account for differences in how non-verbal behavior is decoded. Further, she warned that assuming otherwise could lead to misleading inferences. For example, a number of studies suggest that young white and middle class individuals are better decoders than young black and lower class individuals. However, these differences disappear in some cases and even reversed, as individuals grow older. In sum, the available research indicate that the diverse audiences of charismatic leaders will not always perceive, interpret and react to their non-verbal behaviors in the same way. Hence, it is critical for charismatics leaders to recognize the impact of individual differences on audience reactions to their performance. This implies:

Proposition 9: The follower's skill at reading non-verbal cues is a critical determinant of user reactions to the charismatic leader's non-verbal behavior.

\section{Need for Social Approval}

One individual difference variable that is especially relevant to the charismatic relationship is the followers' needs for social approval. People with high needs for approval are especially sensitive to the messages (both verbal and non-verbal) communicated by others. Crowne and Marlowe (1964) developed social desirability scale to measure individual needs for approval. Research using this scale indicates that people who are highly sensitive to the approval of others are less likely to interrupt others when they speak, communicate less negativity with their face and voice, and speak in a manner that reflects the intensity of their partner's speech (DePaulo, 1992). Accordingly, followers with high versus low needs for approval are expected to be more attuned to the leaders' nonverbal behaviors and show more favorable reactions such as head nodding and smiling. Thus, it is proposed that: 
Proposition 10: Followers with high as opposed to low needs for social approval react more positively to the charismatic leader's non-verbal behavior.

\section{Favorability}

Charismatic leadership is based on its effect on followers. After all, one major element separating charismatic from non-charismatic relationships is the strong emotional attachment of the follower to the leader (e.g., Bass, 1985). When followers attribute charisma to leaders and perceive them as having a vision and a value system that they identify with (House, 1977), a charismatic relationship is at work. Follower reactions may take a number of forms. These include, dependence on the leader, acceptance, obedience, loyalty, and a collective orientation (Shamir, 1991). However, at the more general level, followers will increase their effort, performance levels, commitment and satisfaction (Awamleh \& Gardner, 1999; Bass, 1985; Howell \& Frost, 1989).

Importantly, in order for followers to attribute charisma, and identify with the leader, they must first form favorable impressions. As noted earlier, such impressions are based, in part, upon the leader's non-verbal behavior. Thus, by carefully selecting and monitoring non-verbal behavior, charismatics can foster desired images that result in favorable reactions from followers.

\section{Conclusions and Suggestions for Future Research}

This paper has presented a model of process whereby charismatic leaders utilize non-verbal behaviors to manage the impressions of prospective and current followers. The model integrates various constructs that are believed to be associated with the charismatic relationship, yet are extremely relevant to the study of non-verbal expressions. The proposed framework can serve as a constructive conceptual guide for integrating divergent streams of testing and steering future inquiries. Such research could begin by testing the propositions advanced.

Efforts to identify and clarify the effects of environmental variables on the critical non-verbal behaviors of charismatic leaders as well as follower impressions would be especially worthwhile. Also, more focus is needed to investigate follower reactions to specific non-verbal behaviors. This line of research will enable scholars and practitioners to utilize charisma in organizations more effectively.

\section{References}

1. Anderson, A. A. (1985). Non-Verbal Immediacy in Interpersonal Communications. In A.W. Seigman \& S. Felstein, Multi channel interactions of Non-Verbal Behavior. Hillsdale, N.J.: Elbraum.

2. Awamleh. R. A. \& Gardner, W. L. (1999). Perceptions of Leader Charisma and Effectiveness: the Effects of Vision Content, Delivery, and Organizational Performance. Leadership Quarterly, 10(3), 345-373.

3. Avolio, B.J. \& Yammarino, F. J. (1990). Operationalizing Charismatic Leadership Using Multi-levelsAnalysis Framework. Leadership Quarterly, 1(3): 193-208.

4. $\quad$ Bass, B.M. (1985). Leadership and Performance Beyond Expectations. New York: Free Press.

5. Bass, B.M. (1990). Bass \& Stogdill's Handbook of Leadership: Theory, Research, \& Managerial Applications $\left(3^{\text {rd }}\right.$ ed.). New York: Free Press.

6. Beattie, G. \& Shovelton, H. (2002). An Experimental Investigation of Some Properties of Individual Iconic Gestures that Mediate Their Communicative Power. British Journal of Psychology. 93(2): 179-192.

7. $\quad$ Cohen, R, (1987). Theater of Power: The Art of Diplomatic Signaling. England: Longman group.

8. Conger. J.A., Kanungo. R.N., \& Associates (1987). Charismatic Leadership: The Elusive Factor in Organizational Effectiveness. San Francisco: Jossey-Bass.

9. $\quad$ Crowne, D. P., \& Marlowe, D. (1964). The Approval Motive. New York: Wiley.

10. DePaulo, B. M. (1992). Non-Verbal Behavior and Self-presentation. Psychological Bulletin, 111(2): 203243.

11. Ekman, P., Davidson, R., Frisen, W. V. (1990). Duchenne's smile: Emotional Expression and Brain Physiology II. Journal of Personality and Social Psychology, 58:342-353. 
12. Ellsworth. P. C. \& Carlsmith, J. M. (1968). Effects of Eye Contact and Verbal Contact On Affective Response To A Dyadic Interaction. Journal of Personality and Social Psychology, 10(1): 15-20.

13. Friedman, H.S. \& Miller-Heringer. T. (1991). Non-Verbal Display of Emotion In Public and In Private: Self-Monitoring, Personality, and Expressive Cues. Journal of Personality and Social Psychology, 61(4): 766-775.

14. Gardner, W. L. \& Avolio, B. J. (1998). The Charismatic Relationship: A dramaturgical perspective. Academy of Management Review, 23: 32-58.

15. Gardner, W. L. \& Martinko, M. J. (1988). Impression Management In Organizations. Journal of Management, 14(2): 321-338.

16. Gitter, A. G., Black, H., \& Fishman, J. E. (1975). Effects of Race, Sex, Non-Verbal Communication and Verbal Communication on Perception of Leadership. Sociology and Social Research, 60 (1): $46-57$.

17. Kraut, R. E., \& Johnston, R. E. (1979). Social and Emotional Messages of Smiling: An Ethological Approach. Journal of Personality and Social Psychology, 37:1539-1553.

18. Hall, J. A. (1984). Non-Verbal Sex Differences: Communication Accuracy and Expressive Style. Baltimore: Johns Hopkins University press.

19. Hall, J. A., Horgan, T. G., \& Carter, J. D. (2002). Assigned and Felt Status In Relation To Observer-Coded and Participant-Reported Smiling. Journal of Nonverbal Behavior, 26(2): 63-81.

20. Harrison, R. P. (1974). Beyond Words: An Introduction To Non-Verbal Communication. Englewood Cliffs, N. J.: Prentice Hall.

21. Holladay, S. J. \& Coombs, W. T. (1993). Communicating Visions: An Exploration of the Role of Delivery In The Creation Of Leader Charisma. Management Communication Quarterly, 6(4): 405-427.

22. House, R. J. (1977). A 1976 Theory of Charismatic Leadership. In J. G. Hunt \& L. L.

23. Larson (Eds.), Leadership; The Cutting Edge, 189-204. Carbondale, IL: Southern Illinois University press.

24. House, R. J., \& Baetz, M. (1979). Leadership: Some Empirical Generalizations and New Research Directions. In L. L. Cummings \& B. M. Staw (Eds), Research in Organizational Behavior, Vol. 1: 341423. Greenwich, CT: JAI press.

25. House, R. J., \& Howell, J. M. (1992). Personality and Charismatic Leadership. Leadership Quarterly, 3(2): 81-108.

26. La France, M. \& Hecht, M. A. (2000). Gender and Smiling: A Meta-Analysis. In A. H.

27. Fischer (ed.) Gender and Emotion: Social Psychological Perspectives. (pp. 118-142). Cambridge University Press, Paris.

28. Leary, M. R. (1989). Self-Presentation Process In Leadership. In R. A. Giacolone \& P.

29. Rosfield (Eds), Impression Management In Organizations: 363-374. Hillsdale, N. J.: Eelbaum.

30. Leary, M. R., \& Kowalski, R. M. (1990). Impression Management: A Literature Review and TwoComponent Model. Psychological Bulletin. 107: 34-47.

31. Howell, J. M., \& Frost, P. J. (1989). A Laboratory Study of Charismatic Leadership. Organizational Behavior and Human Decision Process, 43: 243-269.

32. McAdams, D. P., Jackson, R. J. \& Kirsshnit, C. (1984). Looking, Language, and Smiling In Dyads As A Function Of Intimacy Motivation And Reciprocity. Journal of Personality, 52: 261-273.

33. McHugo, G. J., Lanzetta, J. T., Sullivan, D. J., Masters, R. D., \& Englis, B. G. (1985).

34. Emotional Reactions To A Political Leader's Expressive Displays. Journal of Personality and Social Psychology, 49(6): 1513-1529.

35. Masters, R. D. (1991). Individual and Cultural differences in Response to Leaders' Non-Verbal displays. Journal of Social Issues, 47(3): 151-165.

36. Masters, R. D., \& Sullivan, D. G. (1989). Non-Verbal Displays and Political Leadership in France and the United States. Political Behavior, 11: 121-153.

37. Miller, P. W. (1988). Non-Verbal Communication. Washington, DC. : National education association.

38. Mullen, B., Futrell, D., Stairs, D., Tice, D. M., Baumeister, R. F., Dawson, K. E.,

39. Riordan, C. A., Radloff, C. E., Geothels, G. R., Kennedy, J. G., \& Rosenfeld, P. (1986). Newscasters' Facial Expressions and Voting Behavior of Viewers: Can A Smile Elect A President? Journal of Personality and Social Psychology, 51(2): 291-295.

40. Nasby, W., Hayden, B., \& DePaulo, B. M. (1980). Attributional Bias Among Aggressive Boys to Interpret Unambiguous Social Stimuli as Hostile Displays. Journal of Abnormal psychology, 89: 459-468. 
41. Rasmussen, K. G. (1984). Non-verbal behavior, Verbal behavior, Resume credentials, and Selection interview outcomes. Journal of Applied Psychology, 69(4): 551-556.

42. Remland, M. (1984). Leadership Impressions and Non-Verbal Communication in a Superior-Subordinate Interaction. Communication Quarterly, 32(1): 41-48.

43. Riggo, R, E., \& Friedman, H. S. (1986). Impression Formation: The Role of Expressive Behavior. Journal of Personality and Social Psychology, 50(2): 421-427.

44. Shamir, B. (1991). The Charismatic Relationship: Alternative Explanations and Predictions. Leadership Quarterly, 2(2): 81-104.

45. Synder, M. (1974). Self-Monitoring of Expressive Behavior. Journal of Personality and Social Psychology, 30(4): 526-537.

46. Sullivan, D. G., \& Masters, R, D. (1988). Happy Warriors: Leaders' Facial Displays, Viewers' Emotions, and Political Support. American Journal of Political Science, 32: 345-368.

47. Sundaram, D. S. \& Webster, C. (2000). The Role of Nonverbal Communication in Service Encounters. Journal of Services Marketing. 14(5): 378-391.

48. Webbink, P. (1986). The Power of The Eyes. New York: Springer Publishing Company.

49. Willner, A. R. (1984). The Spellbinders: Charismatic Political Leadership. New Haven: Yale University press.

Notes 
Notes 